\title{
The Least Developed Countries at Santiago
}

by Percy Selwyn

1. Introduction

The 'Least Developed Countries' were in some respects the success story of UNCTAD III, in that a number of measures were approved which had the ostensible support of the rich countries (partly, perhaps, as a diversion from their lack of support for initiatives in most other areas). In this note I shall first consider the question of 'identification' of the least-developed countries and then examine the relevance and adequacy of some of the resolutions passed at Santiago.

Much work has been done on the identification of the leastdeveloped countries, culminating in the list of 25 'hard-core' least-developed countries produced in 1971 by the U.N. Committee for Development Planning ${ }^{1}$. This broadly included countries with a GNP per head of less than $\$ 100$, a literacy rate of less than 20 per cent and a contribution of manufacturing to GNP of less than 10 per cent. It is clearly intended that this work should continue. Before looking at what has been achieved, it is worth considering the whole notion of identification. The implicit assumption of all this work (and the word 'identification' makes this clear) is that there is somewhere a group of countries which have sufficient in common for us to make meaningful statements about them as a group. But classification is not an abstract process; it is carried out to meet the needs of particular people or groups, and is based on implicit assumptions about the nature of the problem to be studied. In this Darticilar case, it is by no means clear what the assumptions and purposes behind the classification are, and different groups clearly have different assumptions and purposes in mind. It may be useful to consider first, what it is that the classification is intended to

\footnotetext{
* Percy Selwyn is an IDS Fellow.

${ }^{1}$ Committee for Deve Zopment. P Zanning: Report on the Seventh Session, 22 March - 1 April 1971. New York, United Nations 1971.
} 
show, and secondly what is the framework within which the classification has to be carried out.

2. Defining the 'least-developed'.

First, what does the classification 'least-developed' mean?

(a) It may be a welfare classification. The main welfare elements in the identification procedures so far employed are GNP per head and the percentage of literacy. It could be argued that people living in countries defined in this way - taken as a whole and ignoring problems of distribution - are 'worse off' than people living in other countries. But if this is the meaning, welfare is clearly being looked at in a very restricted way, and the virtual omission of political, social or distributional criteria, or any measure of the 'quality of life' (however defined) is very limiting. Moreover, as I shall point out later, to define welfare in terms of countries rather than of people gives oddly distorted results.

(b) The classification has Rostovian overtones. It may be intended to imply that there are stages of development and that these countries are at the first or most primitive one. Such an approach could possibly be of analytical interest to students of the subject though it may also be of little practical or operational utility. But an examination of the list lends little support to this interpretation. Can a country such as Haiti which was a major sugar producer and exporter 200 years ago and has been 'integrated' into the world economy for 300 years usefully or in any meaningful sense be regarded at this most primitive stage of development? It is however true that some of the countries listed, such as Nepal, Yemen and Ethiopia, can usefully be categorised in this way.

(c) The classification may refer to structure. It may be supposed that there is an economic or social structure which is found in the 'least-developed country' and which is not found in other countries. Various elements of such a structure have been identified - a high proportion of primary and correspondingly low proportion of secondary production in total output, low agricultural productivity and so on. There seem to me to be several difficulties in this approach. First these structural elements are found in many poor countries whether or not they are classed as least-developed - that is, any sensible classification according to structure will probably cut across the category of least-developed countries. Secondly, the mere identification of these elements in structure tells us very little about the dynamic elements in the situation. Thus in some poor countries (whether classed as least-developed or not) we can identify factors making for stagnation or even retrogression; in others, it 
is possible to argue that, although now very poor and backward, they have reasonable possibilities for advance if certain conditions are fulfilled. Lastly, the apparent similarity in structure of the group of 25 identified countries may be partly spurious, since the criteria may be inter-dependent. Thus, although there may be exceptions due to special circumstances, a country with a very low level of average income will tend to have a low level of literacy, merely because it cannot afford to spend much on education. Similarly, countries with a very low average level of income will normally have a low proportion of total value added deriving from industry, because output per head in industry is normally much greater than in subsistence agriculture. (A small industrial sector is also associated with small size of country 1 and it is significant that 17 of the list of hard-core countries have populations of less than 5 million and a further 3 have populations of less than 10 million.) Rut all this tells us very little about structure in any helpful or practical sense. This was implicitly recognised by the recent expert groups who emphasised the need for country-by-country studies rather than further generalisations about least-developed country structures as a whole.

(d) Lastly, we may be identifying, not so much countries, as problems. The classification may be intended to emphasise that there are certain identifiable problems which, while applying in some degree in many countries, present particular difficulties in some countries. This approach would imply that the search for criteria leading to an identification of a clearly defined list of countries is pointless and that what we are really seeking is a series of lists of countries seriously affected by specific problems. These lists may well overlap and some countries may be found on several such lists.

The definition of least-developed countries in terms of problems in fact corresponds closely to the policy discussions which have taken place on special measures for their benefit. These have normally been in the context of the interests of the organisations in which these discussions have taken place - and in particular, the various agencies of the United Nations. They have therefore been concerned with problems of concern to these organisations - especially with aid, trade and regional relations. These have in practice defined the area of discussion even though the process of identification has been carried out in a totally different context.

${ }^{1}$ s. Kuznets, Economic Growth of Nations, Harvard University Press, 1971, pp. 118-126. 
What then has the process of identification achieved so far? A cynical answer might be that it has produced a 1 ist of countries meeting certain arbitrary criteria laid down for least-developed countries - except in so far as there are countries whose statistics are so poor that it is not possible to say whether they meet the criteria or not. In other words, we now have a more or less agreed list of countries with an average income of less than $\$ 100$, with less than 20 per cent adult literacy and an industrial contribution to GNP of less than 10 per cent. Since the 1 ist has been produced in the context of special measures for assisting such countries, one of its main effects has been to raise objections from very poor countries not on the list to the effect that they should be on it, as well as from countries with no prospects of being classified as least-developed countries and which fear (not entirely unjustifiably) that measures in favour of countries on the 1 ist will be at their expense. Thus the process of identification has become a political issue. But the whole concept of 'least-developed country' cannot in any event be divorced from politics. Since the classification has emerged in international institutions and groups dealing with or representative of nation states, it has taken the nation state as its unit of consideration. But many similar considerations apply to the backward areas in larger countries as to least-developed states as such. Thus before Zambia became independent there was some pressure from the traditional rulers in Barotseland for the establishment of a separate Barotse state. If it had been established, it would certainly have been on the list of least-developed countries. Since it has not, Barotseland has become an internal Zambian problem. But the nature and problems of the Barotse economy are not substantially different from what they would have been if Barotse land had been a separate state. Thus the whole identification exercise has taken place within a politically defined framework and this framework has dictated the area of concern.

The use of the nation state as the unit of consideration has another implication. Most nation states in the third world are sma11. Some 45 per cent of the member countries of the U.N. in 1971 had populations of less than 5 million and a further 15 per cent had populations between 5 and $10 \mathrm{million}$. It has already been pointed out that 17 of the 1 ist of 25 least-developed countries have populations of less than 5 million and a further 3 have populations of less than 10 million. Clearly this emphasis on small countries in the identification of least-developed countries is very largely a retlection of the political framework in which the process of identification has taken place (although, as has been pointed out, it also reflects the use of industrial development as one of the criteria employed). If, instead of countries, the unit had been, say, people, a very different picture would have emerged. Thus (taking an 
explicit welfare criterion, if we were to try to identify actual numbers of people falling below certain minimum standards, obviously most of these would be found in large countries such as India.

3. An alternative approach

But in spite of these limitations, the work on the least-developed countries has brought up a number of serious and important problems, which can be most conveniently considered in the context of the discussions at Santiago. These, as I have said, relate to the principal interests of UNCTAD - that is, to aid, trade and regional institutions.

On aid, one central problem which has been identified is that there are certain countries with a low absorptive capacity for new investment, either because of administrative limitations or because the type of investment needed, e.g. in social or physical infrastructure, has a very low rate of return. Indeed, in the short run, some investments have a negative rate of return, i.e. the cost of maintaining or running the new services may be greater than their short-term benetit. Whether or not such investment is worthwhile must depend on our time-scale - that is, what rate of discount is applied to long-term benetits. Here it is argued that the use of conventional rates of discount will rule out most projects, so that there is a need for a different set of evaluation criteria from those used in other countries.

To some extent the resolutions adopted at UNCTAD III show an appreciation of this problem. They point to the need tor, "ensuring that... assistance is not guided solely by financial criteria but that consideration is given to the long-term social rate of return, including secondary effects, from development projects." and again, "...to ensure that financial and technical assistance takes into account the long-term nature of the least-developed countries' development problem." This could be read as implying the adoption of a different set of criteria, and in particular a different set of discount rates, for the evaluation of projects from least-developed countries. It is not clear whether this is the intention. Such differential treatment is indeed already implied in the distinction between IDA countries and other countries, but IDA countries are of course a much wider group than the least-developed countries.

The difficulty in the resolution is the identification process with which it is allied. Is it reasonable to suppose that there is a group of 25 countries where projects should be evaluated on a different basis from that used in all other poor countries? If, however, we take the problem approach to the least-developed 
countries, the difficulty disappears. We can reasonably argue that there are countries where development is going to be a very longterm process and that any system of evaluation which ignores longterm benefits because of the use of high discount rates will have the effect of ruling out virtually any development effort. The conclusion might be that bilateral and multilateral aid agencies should be ready to adopt a flexible approach to the choice of criteria and should adapt them to the specific circumstances and needs of the country concerned.

This, although an advance, still leaves many gaps. For example, if development is to be a long-term process, any development strategy must be long-term too and there must be some degree of assurance that resources will be available over a substantial period to meet development objectives. But donors generally do not like to enter into long-term commitments. There is clearly a whole area of policy to be explored: how to make resources available on a long-term and assured basis to countries of this kind, whether through some adaptation of the SDR system or through the creation of a special fund (a proposal which received little support from the rich countries at Santiago).

A study of these needs and of the desirability and feasibility of setting up a special fund is to be made following UNCTAD III. There is another aspect of aid policy which the resolution does not mention: the need for budgetary aid under whatever name. If the short-term effect of investment is to create budgetary difficulties, the budget itself becomes a major constraint on development planning. I have argued elsewhere against the artificial - and indeed quasi-theological - distinction which aid donors make between 'development' aid and budgetary aid ${ }^{1}$. Although the point is made in the UNCTAD Secretariat proposals before the conference, it is not clearly reflected in the resolution itself. Budgetary aid notoriously creates political and administrative problems for both donor and recipient countries, but these problems need to be met and not ignored.

On the trade side, the main problem which has been identified is that there are certain countries which have benefited and seem likely to benefit to only a very small extent from the concessions which the rich countries have made in earlier sessions of UNCTAD in particular from the generalised system of preferences. Since this

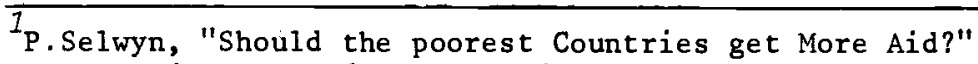

Intemational Development Review, September 1969. 
arrangement is restricted to manufactures, it is clearly of little benefit to countries with very small industrial sectors and even smaller industrial exports. Here UNCTAD III marks some distinct progress. If the resolutions are implemented (which, if we may judge from experience, is by no means certain) the system should eventua1ly be extended to cover processed and semi-manufactured products, and its period of operation should be extended to allow some of the countries which do not at present benefit from it to do so. The resolution also states that escape clause measures introduced by preference-giving countries should remain exceptional and should be decided on only after due account has been taken (as far as their legal provisions permit) of the interest of the least-developed countries.

Again, apart from the vagueness and the lack of teeth in such a resolution, the interests of the least-developed countries in this field are not substantially different from those of many other poor countries with a low level of manufactured exports. Indeed, any relaxation of escape clause measures specifically in favour of leastdeveloped countries would discriminate against other poor countries. The resolution does not suggest such discrimination, and it is highly unlikely that any resolution along such lines would have been accepted. The only reasonable interpretation of the resolution is that escape clause procedures should be exceptional in respect of products of interest to least developed countries, i.e. processed products and semi-manufactures. Again, what appears on the surface to be a measure specially related to the problems of least-developed countries should on this interpretation be of interest to a far wider group of countries. What is of major concern is how this is interpreted by the main importing countries or trading areas. The short-term prospects are hardly favourable. Those least-developed countries which at present benefit from Commonwealth Preferences (Botswana, Lesotho, Malawi, Tanzania and Uganda) will shortly come under the more restrictive EEC rules of access for processed products and semi-manufactures. Possibly the first test of the meaning of the resolution will occur when it is seen what terms these countries (and others similarly situated) obtain trom the European Community.

Lastly, there is the matter of the regional problems of the least-developed countries. A cursory examination of the list of 25 'hard-core' countries suggests that most of them are peripheral areas in the regions in which they are situated, and that they suffer from the polarisation processes common to nuclear regions. Thus the regional dimension of their problems may be of central importance and, in so far as regional issues are of concern to UNCTAD, this is also reflected in the resolutions. The difficulty in this policy 
area is that, whereas in the fields of aid and world trade the developing countries at UNCTAD were seeking concessions from the developed countries, in this field concessions are being sought mainly (though not entirely) from other developing countries. Thus the resolutions on regional groupings suggest "aspects (which) should be studied with a view to facilitating the association of the leastdeveloped countries." These include permission to impose quantitative restrictions, temporary exemption from alignment of tariffs, the granting of greater fiscal incentives for new investment, preferential allocation of regional financial resources, first choice in the location of industries and the extension of regional commodity agreements. All these measures involve some sacrifice by the more advanced countries in the region. It is possible that such concessions may be offered on purely commercial considerations - that is, that the gains obtained by the more advanced countries in regional associations may be sufficient for it to be worth their while to make concessions to their weaker partners. But the resolution clearly implies more than this. It suggests a deliberate policy of operating regional associations in such a way as to be of special assistance to the leastdeveloped countries - in other words, that action in favour of some poor countries should be at the expense of other poor countries. Is such a policy practicable unless it is in some way supported by concessions or assistance from the developed countries? The only reference the Santiago resolutions make to the possibility of such help is in relation to regional development banks, which are to be encouraged to widen their participation in the tinancing of small-scale projects in the least-developed countries or of regional multinational projects involving such countries. This is presumably to be associated with an increase in the resources to be made available to such banks. It may be doubted whether this is adequate for a really effective policy of shaping the regional institutions in such a way as to be of assistance to their least-developed members.

Here too, the problem is not confined to the so-called leastdeveloped countries. In regional associations such as LAFTA, CACM, and CARIFTA, the polarisation of development is a key issue, even though none of their members are on the list of 25 hard-core leastdeveloped countries. Special arrangements have been found necessary for dealing with the problem in all these areas.

4. Conclusions

To sum up, discussing the issue in terms of a list of identifiable countries tends to be unhelpful; indeed one expert group suggested a special classification of 'comparatively disadvantaged' countries in regional terms in order to meet this difticulty ${ }^{1}$. But

\footnotetext{
$1_{\text {Report of the ad hoc Group of Experts on special measures in favour }}$ of the least-developed among the developing countries, UNCTAD $\mathrm{TD} / \mathrm{B} / 349,19$ May 1971 .
} 
a classification of 'least development' in terms of problems rather than countries would surely be more helpful in this context. By so doing, we would be identifying the issue whether it arose in Lesotho (which is on the list) or in Dominica or Paraguay (which are not).

I would argue, then, that the process of seeking for special measures in favour of the least-developed countries has been confused and hindered by the identification process with which it has been associated. There is a range of problem areas, to which we may usefully apply the term 'least development' and where sensible international action could make a useful impact. But the attempt tc associate an approach to these problems with a limited and specified group of countries both hinders their solution in political terms and directs attention away from the real issues involved.

It is true that the problem approach itself involves ditficulties, for problems cannot be considered in isolation. Obviously the situation of a country with a high level of illiteracy and very low average incomes is different from one where a high illiteracy rate is associated with higher incomes but also with substantial social and economic inequalities - that is, where resources are available locally for improving educational standards, but where decisionmakers are not concerned with providing education for the people. Any international agency concerned with this problem should obviously take all the circumstances into account in arriving at a policy. But this procedure, although complicated and sometimes difficult, raises fewer problems than does the attempt to take action on the basis of a discreet and limited number of countries. What is needed is a degree of flexibility and a willingness to study the problems and the contexts in which they arise, rather than an attempt to prejudge the issue by means of an arbitrary exercise in identification. 